\title{
Upper Limit of Quantitation
}

National Cancer Institute

\section{Source}

National Cancer Institute. Upper Limit of Quantitation. NCI Thesaurus. Code C85533.

The highest value in a standard range of values. 